University of Wollongong

Research Online

Faculty of Engineering - Papers (Archive)

Faculty of Engineering and Information

Sciences

2012

\title{
Analysis of $\mathrm{N}$-nitrosamines in water by isotope dilution gas chromatography-electron ionisation tandem mass spectrometry
}

James A. McDonald

University Of New South Wales

Nick B. Harden

Agilent Technologies

Long Nghiem

University of Wollongong, longn@uow.edu.au

Stuart J. Khan

University Of New South Wales, s.khan@unsw.edu.au

Follow this and additional works at: https://ro.uow.edu.au/engpapers

Part of the Engineering Commons

https://ro.uow.edu.au/engpapers/5059

\section{Recommended Citation}

McDonald, James A.; Harden, Nick B.; Nghiem, Long; and Khan, Stuart J.: Analysis of N-nitrosamines in water by isotope dilution gas chromatography-electron ionisation tandem mass spectrometry 2012, 146-154.

https://ro.uow.edu.au/engpapers/5059

Research Online is the open access institutional repository for the University of Wollongong. For further information contact the UOW Library: research-pubs@uow.edu.au 


\title{
Analysis of $\mathrm{N}$-nitrosamines in water by isotope dilution gas chromatography-electron ionisation tandem mass spectrometry
}

\author{
James A. McDonald ${ }^{\mathrm{a}}$, Nick B. Harden ${ }^{\mathrm{b}}$, Long D. Nghiem ${ }^{\mathrm{c}}$, Stuart J. Khan ${ }^{\mathrm{a}, *}$ \\ ${ }^{a}$ UNSW Water Research Centre, School of Civil and Environmental Engineering, University of New South Wales, NSW 2052, Australia \\ ${ }^{\mathrm{b}}$ Agilent Technologies, Australia and New Zealand \\ c Strategic Water Infrastructure Laboratory, School of Civil Mining and Environmental Engineering, University of Wollongong, NSW 2522, Australia
}

\section{A R T I C L E I N F O}

\section{Article history:}

Received 19 March 2012

Received in revised form

17 May 2012

Accepted 18 May 2012

Available online 25 May 2012

Keywords:

Disinfection byproducts

Electron impact ionisation

GC-MS/MS

\begin{abstract}
A B S T R A C T
A method has been developed for the determination of eight $N$-nitrosamines in drinking water and treated municipal effluent. The method uses solid phase extraction (SPE), gas chromatography (GC) and analysis by tandem mass spectrometry (MS-MS) with electron ionization (EI). The target compounds are $N$-nitrosodimethylamine (NDMA), $N$-nitrosomethyethylamine (NMEA), $N$-nitrosodiethylamine NDEA), $N$-nitrosodipropylamine (NDPA), $N$-nitrosodi- $n$-butylamine (NDBuA), $N$-nitrosodiphenylamine (NDPhA), $N$-nitrosopyrrolidine (NPyr), $N$-nitrosopiperidine (NPip), $N$-nitrosomorpholine (NMorph). The use of direct isotope analogues for isotope dilution analysis of all analytes ensures accurate quantification, accounting for analytical variabilities that may occur during sample processing, extraction and instrumental analysis. Method detection levels (MDLs) were determined to describe analyte concentrations sufficient to provide a signal with $99 \%$ certainty of detection. The established MDLs for all analytes were $0.4-4 \mathrm{ng} \mathrm{L}^{-1}$ in a variety of aqueous matrices. Sample matrices were observed to have only a minor impact on MDLs and the method validation confirmed satisfactory method stability over intra-day and inter-day analyses of tap water and tertiary treated effluent samples.
\end{abstract}

(c) 2012 Elsevier B.V. All rights reserved.

\section{Introduction}

$N$-nitrosamines are trace organic contaminants of rapidly growing health and regulatory concern in drinking water and reclaimed effluent. $\mathrm{N}$-Nitrosamines that have previously been identified as drinking water or wastewater contaminants include $\mathrm{N}$-nitrosodimethylamine (NDMA), $\mathrm{N}$-nitrosomethyethylamine (NMEA), $N$-nitrosodiethylamine NDEA), $N$-nitrosodipropylamine (NDPA), $N$-nitrosodi-n-butylamine (NDBuA), $N$-nitrosodiphenylamine (NDPhA), $N$-nitrosopyrrolidine (NPyr), $N$-nitrosopiperidine (NPip), and $N$-nitrosomorpholine (NMorph).

Abbreviations: CI, Chemical ionization; DCM, Dichloromethane; DOC, Dissolved organic carbon; EI, Electron ionisation; GC, Gas chromatography; HLB, Hydrophilic lipophilic balance; IDL, Instrument detection level; LLD, Low level of detection; LOD, Level of detection; MDL, Method detection level; MRM, Multiple reaction monitoring; MS, Mass spectrometry; NDBuA, $N$-nitrosodi- $n$-butylamine; NDEA $\mathrm{N}$-nitrosodiethylamine; NDMA, $\mathrm{N}$-nitrosodimethylamine; NDPA, $\mathrm{N}$-nitrosodipropylamine; NMEA, $N$-nitrosomethyethylamine; NPip, $N$-nitrosopiperidine; NMorph, $N$-nitrosomorpholine; NPyr, $N$-nitrosopyrrolidine; Q, Quadrupole; SPE, Solid phase extraction

* Corresponding author. Tel.: +612 93855070; fax: +61293138624.

E-mail addresses: jamesmcdonald@unsw.edu.au (J.A. McDonald), nick_b_harden@agilent.com (N.B. Harden), longn@uow.edu.au (L.D. Nghiem), s.khan@unsw.edu.au (S.J. Khan).
The formation of $N$-nitrosamines, specifically NDMA, in treated sewage and environmental waters has been known for around 40 years [1]. However, these chemicals have not been recognised as important drinking water contaminants until quite recently. The increased attention has arisen largely as a result of reports during the last decade showing that $\mathrm{N}$-nitrosamines could be commonly formed as disinfection byproducts during chloramination of wastewaters [2] and drinking waters [3,4].

Since then it has been shown that a much wider range of disinfection processes including chlorine dioxide, ozone, and even chlorine in combination with ultraviolet or advanced oxidation processes, could lead to increased formation of $\mathrm{N}$-nitrosamines in drinking waters [5,6]. More recently it has been revealed that $\mathrm{N}$-nitrosamines can also be formed during chlorination and chloramination in the presence of quaternary amines including quaternary amine-based coagulants increasingly used in drinking water treatment $[7,8]$.

In addition to formation during disinfection processes, $\mathrm{N}$-nitrosamines can contaminate source waters to drinking water treatment plants, particularly those that are downstream of discharge points of wastewater treatment plants. Recent evidence suggests that industrial or commercial discharges may lead to high concentrations of these chemicals in raw sewage [9]. Wastewater treatment plants that chlorinate effluents prior to 
discharge, but do not achieve breakpoint chlorination, can produce even greater quantities of $N$-nitrosamines [10].

Regulation of $N$-nitrosamines in drinking waters is rapidly increasing in many parts of the world. NDMA is currently regulated in the Province of Ontario, Canada, at $9 \mathrm{ng} \mathrm{L}^{-1}$ [11]. A Canadian national drinking water guideline for NDMA is also under development [12]. The California Department of Public Health (CDPH) has set a notification level for NDMA of $10 \mathrm{ng} \mathrm{L}^{-1}$ and five $N$-nitrosamines (NDMA, NDEA, NDPA, NDPhA and NPyr) have now been included in the final US EPA Drinking Water Contaminants List 3 [13]. Guideline concentrations for NDMA and NDEA (both $10 \mathrm{ng} \mathrm{L}^{-1}$ ) were included in the Australian water recycling guidelines for the planned augmentation of drinking water supplies [14].

The World Health Organization Guidelines for Drinking Water Quality have recently included a guideline for NDMA of $100 \mathrm{ng} \mathrm{L}^{-1}$ [15]. This was based on an estimated upper-bound excess lifetime cancer risk of $10^{-5}$, the benchmark most commonly used by the WHO for setting health-based guidelines. Consistent with this, recent Australian drinking water guidelines have also included a health-based guideline value of $100 \mathrm{ng} \mathrm{L}^{-1}$ for NDMA [16]. $\mathrm{N}$-nitrosamines were among the highest ranked emerging disinfection byproducts in a recent prioritization process for future public health regulation [17].

The most commonly cited analytical method for the trace analysis of $N$-nitrosamines in drinking water is the US EPA Method 521 [18] and minor variations of it. This method is based on gas chromatography (GC) with chemical ionization (CI) tandem mass spectrometry (MS/MS). During the development of this method, electron ionization (EI) was also assessed, but was determined to be unable to provide sufficient sensitivity to for the analysis of $N$-nitrosamines at low $\mathrm{ng} \mathrm{L}^{-1}$ concentrations [19]. Accordingly, CI has since been adopted for practically all GC-MS methods reported for the trace analysis of $\mathrm{N}$-nitrosamines in water. Recent examples include Hung et al. [20] and Llop et al. [21]. The most common alternative to this has been analysis by high pressure liquid chromatography with tandem mass spectrometry (HPLC-MS/MS) [22-24]. Other advanced methods have included gas chromatography-high resolution mass spectrometry with EI [25] and nanoelectrospray ionisation (NSI) with high-field asymmetric waveform ion mobility spectrometry with time-of-flight mass spectrometry [26]. However, surprisingly little attention appears to have been paid to the possibility of improved sensitivity of a low resolution triple-quadruple GC-MS/MS method using EI.

The increasing regulation of $N$-nitrosamines will require many water utilities to take up routine or occasional monitoring for these chemicals. However, very few Australian water utilities currently have affordable access to GC-MS/MS instruments enabled for chemical ionisation and this situation is likely to prevail also in many other countries. Even fewer utilities have affordable routine access to HPLC-MS/MS or high resolution mass spectrometry. Bench-top GC-MS/MS with EI is rapidly gaining prominence in many environmental and water quality control laboratories around the world. Accordingly, a sensitive and reliable analytical method for the analysis of $\mathrm{N}$-nitrosamines using triple quadrupole GC-MS/MS with EI is of particular interest to the water industry.

\section{Material and methods}

\subsection{Chemicals and SPE materials}

Eight $N$-nitrosamines (NDMA, NMEA, NDEA, NDPA, NDBuA, NPyr, NPip, NMorph), sodium thiosulphate (reagent grade), dichloromethane (DCM) (spectroscopic grade) and methanol (HPLC grade) were purchased from Supelco (St Louis, MO, USA). $\mathrm{N}$-nitrosodimethylamine-D6, $\mathrm{N}$-nitrosodiethylamine-D10, $\mathrm{N}$-nitrosomethylethylamine-D3, $\mathrm{N}$-nitrosodipropylamine-D14, $N$-nitrosodi- $n$-butylamine-D9, $N$-nitrosopyrrolidine-D8, $N$-nitrosopiperidine-D10, $\mathrm{N}$-nitrosomorpholine-D8 were purchased from CDN isotopes (Pointe-Claire, Quebec, Canada). Supelclean coconut charcoal SPE cartridges ( $2 \mathrm{~g}$ bed weight, particle size: 80/ 120 mesh) were purchased from Supelco (St Louis, MO, USA). Ultrapure water was produced using a Driect-Q filtering system (equipped with a UV lamp) from Millipore (North Ryde, NSW, Australia). Kimble culture tubes (13 mm I.D. $\times 100 \mathrm{~mm}$ ) and a Thermo Speedvac concentrator (model No. SPD121P) were purchased from Biolab (Clayton, Vic, Australia). Primary stock standards were prepared for each analyte and isotope-labelled standard in methanol $\left(1 \mathrm{~g} \mathrm{~L}^{-1}, 20 \mathrm{~mL}\right)$ in amber vials and then further serial diluted with methanol to obtain working standard solutions of lower concentrations. All standard solutions were stored at $-18{ }^{\circ} \mathrm{C}$ and prepared freshly every three months. Working solutions of analytes and isotope labelled standards at lower concentrations were stored at $4{ }^{\circ} \mathrm{C}$ and freshly prepared from concentrated stock standards monthly. Chemical structures of target analytes and their isotope labelled standards used in this study are presented in Table 1.

\subsection{Sample collection and preservation}

All samples were collected in clean $500 \mathrm{~mL}$ amber glass bottles with polytetrafluoroethylene (PTFE) lined screw caps. Ultrapure water was produced using a Driect- $Q$ filtering system from Millipore $\left(\mathrm{DOC}=0.1 \mathrm{mg} \mathrm{L}^{-1}\right)$. Drinking water was collected from a regular potable water tap at the University of New South Wales $\left(D O C=2 \mathrm{mg} \mathrm{L}^{-1}\right)$. Tertiary treated effluent was a disinfected final effluent from a municipal wastewater treatment plant in western Sydney $\left(\mathrm{DOC}=15 \mathrm{mg} \mathrm{L}^{-1}\right)$. Residual chlorine was quenched in all tap water and recycled water samples by the addition of approximately $0.5 \mathrm{~g}$ sodium thiosulphate per $500 \mathrm{~mL}$ sample.

Samples were spiked with stock solutions of all analytes for method recovery and detection level determination. The target concentrations of analytes were dependent on the specific experiments as described in method validation studies section below. All samples were then further spiked with isotope labelled standards for accurate isotope dilution quantification $(25 \mu \mathrm{L}$ of a $1 \mathrm{mg} \mathrm{L}^{-1}$ stock in methanol). Spiked ultrapure water and tap water samples were extracted without any further treatment or processing. All samples were extracted within $24 \mathrm{~h}$ of collection and spiking.

\subsection{Solid phase extraction}

The SPE protocol closely followed that of the US EPA method 521 [18]. Coconut charcoal SPE cartridges were conditioned by sequentially rinsing with dichloromethane $(6 \mathrm{~mL})$, methanol $(6 \mathrm{~mL})$ and ultrapure water $(12 \mathrm{~mL})$. A sample volume of $500 \mathrm{~L}$. was then drawn through the SPE cartridges under vacuum and at a flow rate not exceeding $5 \mathrm{~mL} \mathrm{~min}^{-1}$. After loading, cartridges were rinsed with ultrapure water $(3 \mathrm{~mL})$ and dried under a gentle stream of nitrogen. Unless eluted immediately, loaded cartridges were stored at $4{ }^{\circ} \mathrm{C}$ in sealed bags in the dark. Analytes were eluted from the cartridge with dichloromethane $(4 \times 3 \mathrm{~mL})$ into $20 \mathrm{~mL}$ glass tubes. Approximately $100 \mu \mathrm{L}$ of toluene was added to the eluant minimize evaporative loss of analytes during solvent removal. The extracts were concentrated under a stream of nitrogen to approximately $1 \mathrm{~mL}$ using a Turbovap LV (Caliper Life Sciences, Hopkinton, MA, USA) and then transferred to $2 \mathrm{~mL} \mathrm{GC}$ vials for instrumental analysis. 
Table 1

Chemical structures of investigated nitrosamines.

\begin{tabular}{|c|c|c|c|}
\hline Compound & Molecular mass (g/mol) & Abbreviation & Structure \\
\hline $\mathrm{N}$-nitrosodimethylamine & 74.05 & NDMA & \\
\hline$N$-nitrosomethylethylamine & 88.06 & NMEA & \\
\hline$N$-nitrosodiethylamine & 102.08 & NDEA & \\
\hline$N$-nitrosodipropylamine & 130.11 & NDPA & \\
\hline$N$-nitrosomorpholine & 116.06 & NMorph & \\
\hline$N$-nitrosopyrrolidine & 100.06 & NPyr & \\
\hline$N$-nitrosopiperidine & 114.08 & NPip & \\
\hline$N$-nitrosodi- $n$-butylamine & 158.14 & NDBuA & \\
\hline
\end{tabular}

\subsection{Gas chromatography--tandem mass spectrometry}

Samples were analysed on an Agilent 7890A gas chromatograph (GC) coupled with an Agilent 7000B triple quadrupole mass spectrometer (MS/MS).

The GC inlet was operated in splitless mode, held at a temperature of $280^{\circ} \mathrm{C}$ and lined with a single tapered deactivated inlet liner ( $4 \mathrm{~mm}$, Aglient Technologies). An injection volume of $1 \mu \mathrm{L}$ was used. Analytes were separated on an Agilent DB-1701P, $(30 \mathrm{~m} \times 0.25 \mathrm{~mm}, 0.25 \mu \mathrm{m}$ film thickness) column using a $1.2 \mathrm{~mL} \mathrm{m^{-1 }}$ ultrahigh purity helium flow. An injection volume of $1 \mu \mathrm{L}$ was used and the oven temperature programme was as follows; $50{ }^{\circ} \mathrm{C}$ held for $1 \mathrm{~min}$ then raised to $80^{\circ} \mathrm{C}$ at a rate of $10^{\circ} \mathrm{C}$ per min, increased to $180{ }^{\circ} \mathrm{C}$ at $15^{\circ} \mathrm{C}$ per min, increased to $260{ }^{\circ} \mathrm{C}$ at $35^{\circ} \mathrm{C}$ per min and held for $5 \mathrm{~min}$ (total run time $13.8 \mathrm{~min}$ ). The GC/MS-MS interface temperature was maintained at $260{ }^{\circ} \mathrm{C}$.

Mass spectrometric ionisation was undertaken in electron impact (EI) ionisation mode with an EI voltage of $70 \mathrm{eV}$ and a source temperature of $280{ }^{\circ} \mathrm{C}$. The triple quadrupole MS detector was operated in multiple reaction monitoring (MRM) mode with the gain set to 100 for all analytes. In order to identify the most suitable transitions for MRM, analytical standards were initially analysed in scan mode to identify suitable precursor ions in MS1 with a scan range of $m / z 30$ to $m / z M+10$ (where $M$ is the mass of the compound of interest). Fragmentation of the precursor ions in the collision cell was assessed by performing a product ion scan using the same mass range and scan time. Product ion intensity was optimised for each transition by repeated injections at different collision energies. All samples were run with a solvent delay of $4.3 \mathrm{~min}$ and the analytes were separated into 5 discrete time segments for MRM monitoring with dwell times ranging from 10 to $50 \mathrm{~ms}$, depending on the time segment, to achieve 15-30 cycles across each peak for good quantification. All ions were monitored at wide resolution (1.2 amu at half height).

The ion transitions monitored for all analytes and isotope standards, as well as the specific dwell times and collision energies for the method are presented in Table 2. The first MRM transition shown for each molecule was used for quantification while the second transition shown was monitored only for confirmation of molecular identification. A chromatogram showing quantifier peaks of 8 analytes from an injection of $1 \mathrm{pg}$ oncolumn is presented in Fig. 1. Isotopically labelled surrogate standards were observed to consistently elute before the native analyte

by $0.01-0.09 \mathrm{~s}$. This is in accordance with the reverse isotopic effect for chromatographic separation of molecules in the gas phase [27].

\subsection{Identification and quantification}

As described in the previous section, two MRM transitions of a single precursor ion were monitored for each target compound. 
Table 2

GC-MS/MS method parameters.

\begin{tabular}{|c|c|c|c|c|c|}
\hline $\begin{array}{l}\text { Segment } \\
\text { start time }\end{array}$ & $\begin{array}{l}\text { Analytes } \\
\text { and } \\
\text { isotope } \\
\text { standards }\end{array}$ & $\begin{array}{l}\text { Retention } \\
\text { time } \\
(\mathrm{min})\end{array}$ & $\begin{array}{l}\text { MRM } \\
\text { transitions } \\
(\mathrm{m} / \mathrm{z})\end{array}$ & $\begin{array}{l}\text { Collision } \\
\text { energy } \\
\text { (V) }\end{array}$ & $\begin{array}{l}\text { Dwell } \\
\text { time } \\
\text { (ms) }\end{array}$ \\
\hline \multirow[t]{12}{*}{4.3} & \multirow[t]{2}{*}{ NDMA } & \multirow[t]{2}{*}{4.56} & $74.0 \rightarrow 44.1$ & 3 & 20 \\
\hline & & & $74.0 \rightarrow 42.1$ & 7 & 10 \\
\hline & \multirow[t]{2}{*}{ NDMA-D6 } & \multirow[t]{2}{*}{4.55} & $80.0 \rightarrow 50.1$ & 3 & 20 \\
\hline & & & $80.0 \rightarrow 48.1$ & 7 & 10 \\
\hline & \multirow[t]{2}{*}{ NMEA } & \multirow[t]{2}{*}{5.62} & $88.0 \rightarrow 71.0$ & 3 & 50 \\
\hline & & & $88.0 \rightarrow 43.0$ & 5 & 50 \\
\hline & \multirow[t]{2}{*}{ NMEA-D3 } & \multirow[t]{2}{*}{5.6} & $91.0 \rightarrow 74.0$ & 3 & 50 \\
\hline & & & $91.0 \rightarrow 46.0$ & 5 & 50 \\
\hline & \multirow[t]{2}{*}{ NDEA } & \multirow[t]{2}{*}{6.44} & $102.0 \rightarrow 85.0$ & 5 & 80 \\
\hline & & & $102.0 \rightarrow 56.1$ & 10 & 80 \\
\hline & \multirow[t]{2}{*}{ NDEA-D10 } & \multirow[t]{2}{*}{6.39} & $112.1 \rightarrow 94.1$ & 5 & 80 \\
\hline & & & $112.1 \rightarrow 62.0$ & 10 & 80 \\
\hline \multirow[t]{12}{*}{8.2} & \multirow[t]{2}{*}{ NDPA } & \multirow[t]{2}{*}{8.38} & $130.1 \rightarrow 113.0$ & 0 & 20 \\
\hline & & & $130.1 \rightarrow 43.0$ & 10 & 10 \\
\hline & \multirow[t]{2}{*}{ NDPA-D14 } & \multirow[t]{2}{*}{8.31} & $144.0 \rightarrow 126.1$ & 0 & 20 \\
\hline & & & $144.0 \rightarrow 50.1$ & 10 & 10 \\
\hline & \multirow[t]{2}{*}{ NMorph } & \multirow[t]{2}{*}{8.72} & $116.0 \rightarrow 86.0$ & 0 & 20 \\
\hline & & & $116.0 \rightarrow 56.1$ & 10 & 10 \\
\hline & \multirow[t]{2}{*}{ NMorph-D8 } & \multirow[t]{2}{*}{8.7} & $124.0 \rightarrow 94.0$ & 0 & 20 \\
\hline & & & $124.0 \rightarrow 62.0$ & 10 & 10 \\
\hline & \multirow[t]{2}{*}{ NPyr } & \multirow[t]{2}{*}{8.9} & $100.0 \rightarrow 70.0$ & 5 & 20 \\
\hline & & & $100.0 \rightarrow 55.0$ & 5 & 10 \\
\hline & \multirow[t]{2}{*}{ NPyr-D8 } & \multirow[t]{2}{*}{8.86} & $108.0 \rightarrow 78.1$ & 5 & 20 \\
\hline & & & $108.0 \rightarrow 62.1$ & 7 & 10 \\
\hline \multirow[t]{4}{*}{9.15} & \multirow[t]{2}{*}{ NPip } & \multirow[t]{2}{*}{9.11} & $114.0 \rightarrow 97.0$ & 5 & 50 \\
\hline & & & $114.0 \rightarrow 84.0$ & 5 & 20 \\
\hline & \multirow[t]{2}{*}{ NPip-D10 } & 9.07 & $124.1 \rightarrow 106.0$ & 5 & 50 \\
\hline & & & $124.1 \rightarrow 94.0$ & 5 & 20 \\
\hline 10 & NDBuA & 10.26 & $158.0 \rightarrow 141.1$ & 3 & 50 \\
\hline & & & $158.0 \rightarrow 99.0$ & 5 & 20 \\
\hline & NDBuA-D18 & 10.17 & $176.2 \rightarrow 158.0$ & 0 & 50 \\
\hline & & & $176.2 \rightarrow 110.0$ & 5 & 20 \\
\hline
\end{tabular}

Analysis of the acquired data was undertaken using Agilent MassHunter software. The confirmed identification of a target compound was only established once the analysis met all of the identification criteria. These included the observed presence of the two expected transitions at the same retention time, the area ratio of two transitions within a range of $20 \%$ variability with respect to the mean area ratio of all calibration solutions, and a consistent analyte-surrogate relative retention time as that of calibration solutions with relative standard deviation of less than $0.1 \mathrm{~min}$.

\subsection{Calibration}

Quantitative determination of the target analytes was undertaken using external calibration principles combined with the isotope dilution technique. Calibration curves were comprised of at least 5 points out of seven calibration points for the nonlabelled standards $\left(0.5,1,5,10,50,100,200\right.$ and $400 \mathrm{ng} \mathrm{mL}^{-1}$ in DCM) prepared in GC auto-sampler vials. The lowest calibration point used for each analyte was that corresponding to the lowest concentration above the analyte-specific method detection limit (MDL). Each Calibration standard included $50 \mathrm{ng} \mathrm{mL}^{-1}$ of isotopically labelled internal standards. A calibration curve of relative response ratio versus relative concentration ratio of the analyte to internal standard was generated from these standards. A minimum of 5 calibration points was used in all cases, depending on the concentrations of various samples. All calibration curves had a minimum correlation coefficient of 0.99 and the calculated concentration of each calibration standard was required to be within $80 \%-120 \%$ of its true value in order for the sample batch to be considered to have passed quality control criteria.

\subsection{Method validation studies}

Isotope labelled compounds were used as surrogate standards to correct for matrix effects, SPE recovery variability and instrumental variations for the $N$-nitrosamine analytes. Method recoveries of the target analytes were validated in ultrapure water, tap water and tertiary treated effluent.

SPE absolute recoveries were assessed using the spiked ultrapure water, surface water and tertiary treated effluent samples at both a high concentration (100 $\mathrm{ng} \mathrm{L}^{-1}$ ) and a low concentration (10 $\mathrm{ng} \mathrm{L}^{-1}$ ). Since the aim was to assess the loss of the target analytes during SPE extraction, the isotope standards (50 $\mathrm{ng}$ ) were added to the SPE extracts only after the elution step for direct relative comparison to the analytes.

Instrument detection levels (IDLs) were determined for a $1 \mu \mathrm{L}$ injection of standard solution, as the mass of an analyte that produces a signal greater than three times the $\mathrm{S} / \mathrm{N}$ of the instrument [28]. By this criterion, IDLs were determined as an on-column mass of $0.1 \mathrm{pg}$ for NDEA and NDPA, $0.2 \mathrm{pg}$ for NPip and NDBuA, 0.3 pg for NDMA, NMEA, and NMorph and 0.9 pg NPyr.

MDLs were determined in each of the matrices described above according to Method $1030 \mathrm{C}$ from standard methods for the analysis of water and wastewater [28]. For each matrix, seven $500 \mathrm{~mL}$ samples were spiked with target analytes at concentrations close to the expected MDLs. The samples were then spiked with isotopic standards, extracted and analysed through all of the above sample processing and data quantification steps. The seven samples were not analysed sequentially, but were divided into two batches and processed independently on different days to better represent day-to-day variability. MDLs were calculated by multiplying the standard deviation of seven replicates by Student's $T$ value of 3.14 (one-side $T$ distribution for six degrees of freedom at the $99 \%$ level of confidence). Where the calculated MDLs were greater than the actual spiked concentration of any target analytes, a further seven replicates spiked with higher concentrations were analysed to calculate revised MDLs for those analytes. Alternatively, where the calculated MDLs were 5 or more times smaller than the actual spiked concentrations, a further seven replicates spiked with lower concentrations were analysed to calculate revised MDLs. This procedure was repeated until MDLs of all target analytes were determined with a signalto-variability ratio within the bounds of the above criteria.

Instrument stability was assessed on an intra-day and interday basis by injecting a standard solution containing all analytes ( $50 \mathrm{ng} \mathrm{mL}^{-1}$ ) onto the column three times per day over two separate days and comparing the variation in the signal intensity of each analyte standard from these injections. This variation was expressed at the coefficient of variation $\left(C_{v}\right)$ determined as the ratio of the standard deviation $(\sigma)$ to the mean $(\mu)$. The absolute stability of the whole method for measuring surface water and tertiary treated effluent samples was also assessed by processing three samples of each matrix within a day and three additional samples for each matrix on a different day. Note that the instrument stability calculation does not include correction by isotope dilution, but the method stability does.

Matrix assessment was undertaken by spiking all of the target analytes (and isotopic standards) into extracted and reconstituted surface water and tertiary treated effluent matrix samples. These spiked matrix samples were then analysed by GC-MS/MS. The absolute signal of each analyte was compared to a standard solution (prepared in DCM) of the same concentration in order to calculate a percentage signal enhancement or suppression. 


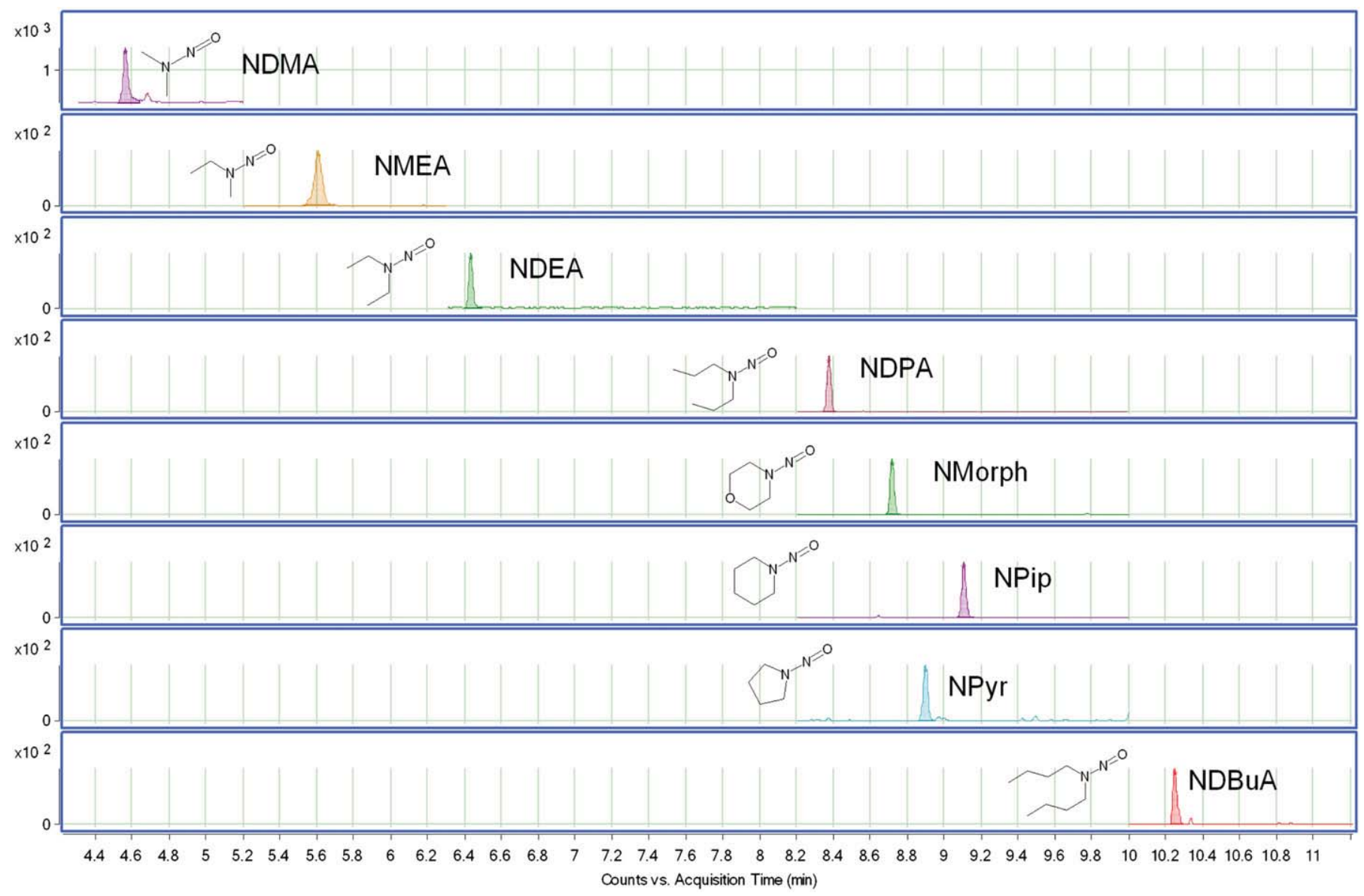

Fig. 1. GC-MS/MS chromatogram of eight $N$-nitrosamines at $1 \mathrm{pg}$ on column.

\section{Results and discussion}

\subsection{Analyte recovery experiments}

Background contamination of $\mathrm{N}$-nitrosamines can present problems for method validation at low $\mathrm{ng} \mathrm{L}^{-1}$ concentrations. Sources of contamination can include rubber consumable products such as latex gloves [29] and pipette bulbs, as well as ion exchange resins used to prepare ultrapure water [30]. Blank (un-spiked) matrix samples were run to assess background concentrations of the analytes in ultrapure water and tap water. A background NDMA concentration of up to $3 \mathrm{ng} \mathrm{L}^{-1}$ was found in tap water samples. This value was variable over time making the use of this matrix for validation problematic. This was overcome by exposing tap water samples to ambient daylight for at least $16 \mathrm{~h}$ after which the background level of NDMA was undetectable. Background levels of five $N$-nitrosamines were also observed in tertiary treated effluent samples. These five $N$-nitrosamines include NDMA (20 ng L $\left.{ }^{-1}\right)$, NDEA ( $\left.5 \mathrm{ng} \mathrm{L}^{-1}\right)$, NMorph $\left(6 \mathrm{ng} \mathrm{L}^{-1}\right)$, $\operatorname{NPip}\left(4 \mathrm{ng} \mathrm{L}^{-1}\right)$ and NDBuA $\left(6 \mathrm{ng} \mathrm{L}^{-1}\right)$. Exposure of this matrix to light was not effective for the removal of these background levels particularly for the larger molecular weight nitrosamines and accurate recovery determination for the compounds present in this matrix was not possible at the $10 \mathrm{ng} \mathrm{\textrm {L } ^ { - 1 }}$ concentration.

The calculated method recoveries of the target compounds in ultrapure water and tap water matrices are shown in Table 3. It was observed that the use of isotope dilution satisfactorily corrected for any loss during sample processing, matrix effects and instrument variation leading to accurate quantification in all tested matrices. For ultrapure and tap water matrices method recoveries for both low $\left(10 \mathrm{ng} \mathrm{L}^{-1}\right)$ and high concentration (100 $\mathrm{ng} \mathrm{L}^{-1}$ ) spikes ranged from $82 \%-102 \%(\max \sigma=10 \%$ ) for all target compounds. As described above, five target compounds (i.e., NDMA, NDEA, NMorph, NPip, and NDBuA) were detected in tertiary treated effluent and thus their recoveries in the $10 \mathrm{ng} \mathrm{L}^{-1}$ spike were not evaluated. For the three nitrosamines (i.e., NMEA, NDPA, and NPyr) which did not occur in tertiary treated effluent, recoveries were in the range between $90 \%$ and $98 \%$ ( $\max \sigma=14 \%$ ) in the $10 \mathrm{ng} \mathrm{L}^{-1}$ spike (Table 3). Method recoveries for all 8 nitrosamines ranged between $81 \%$ and $111 \%$ in the $100 \mathrm{ng} \mathrm{L}^{-1}$ ( $\max \sigma=9 \%$ ) spike where background levels were not so significant relative to the spike. The results of SPE absolute recoveries of the target compounds from low concentration $\left(10 \mathrm{ng} \mathrm{L}^{-1}\right)$ and high concentration (100 $\mathrm{ng} \mathrm{L}^{-1}$ ) spiking tests are presented in Table 4. In tap water the absolute SPE recoveries ranged from $52 \%$ to $94 \%$ when spiked at $100 \mathrm{ng} \mathrm{L}^{-1}$ and from $62 \%$ to $93 \%$ when spiked at $10 \mathrm{ng} \mathrm{L}^{-1}$. Absolute SPE recoveries from ultrapure water were $(51 \%$ to $93 \%)$ when spiked at $100 \mathrm{ng} \mathrm{L}^{-1}$ and $(43 \%-99 \%)$ when spiked at $10 \mathrm{ng} \mathrm{L}^{-1}$. Relatively poor recoveries are observed for the lower molecular weight nitrosamines such as NDMA, NMEA and NPyr because their low log Kow values make them highly water soluble and less likely to partition into non-polar media [31]. Overall absolute SPE recoveries were higher in tap water than in ultrapure water particularly for the low molecular weight nitrosamines suggesting that dissolved inorganics and/or organic carbon in the matrix may enhance the SPE recovery. Absolute SPE recoveries from tertiary treated effluent ranged from $79 \%$ to $101 \%$ when spiked at $100 \mathrm{ng} \mathrm{L}^{-1}$ while when spiked at $10 \mathrm{ng} \mathrm{L}^{-1}$ only compounds not present in this matrix gave meaningful values; NMEA (71\%), NDPA (86\%), NPyr (70\%). 
Table 3

Method recoveries of analytes from spiking concentrations of $10 \mathrm{ng} \mathrm{L}^{-1}$ and $100 \mathrm{ng} \mathrm{L}^{-1}, \mu( \pm \sigma) \%$.

\begin{tabular}{|c|c|c|c|c|c|c|}
\hline \multirow[t]{2}{*}{ Analytes } & \multicolumn{2}{|c|}{ Ultra pure water $n=7$} & \multicolumn{2}{|c|}{ Tap water $n=7$} & \multicolumn{2}{|c|}{ Tertiary treated effluent $n=7$} \\
\hline & $10 \mathrm{ng} \mathrm{L}^{-1}$ & $100 \mathrm{ng} \mathrm{L}^{-1}$ & $10 \mathrm{ng} \mathrm{L}^{-1}$ & $100 \mathrm{ng} \mathrm{L}^{-1}$ & $10 \mathrm{ng} \mathrm{L}^{-1}$ & $100 \mathrm{ng} \mathrm{L}^{-1}$ \\
\hline NDMA & $100(6)$ & $96(5)$ & $90(3)$ & $100(4)$ & * & $111(9)$ \\
\hline NMEA & $92(4)$ & $98(4)$ & $94(4)$ & $102(1)$ & $98(3)$ & $87(4)$ \\
\hline NDEA & $88(6)$ & $92(7)$ & $93(4)$ & $100(2)$ & & $86(6)$ \\
\hline NDPA & $84(8)$ & $93(4)$ & $90(4)$ & $100(3)$ & $92(9)$ & $84(4)$ \\
\hline NMorph & $86(2)$ & $90(5)$ & $92(5)$ & $100(2)$ & & $88(5)$ \\
\hline NPyr & $68(10)$ & $71(10)$ & $82(8)$ & $87(3)$ & $90(14)$ & $81(6)$ \\
\hline NPip & $72(4)$ & $76(6)$ & $86(6)$ & $93(3)$ & * & $94(4)$ \\
\hline NDBuA & $94(9)$ & $91(3)$ & $104(7)$ & $98(3)$ & ${ }^{*}$ & $90(4)$ \\
\hline
\end{tabular}

* Background levels were observed for these compounds in tertiary treated effluent.

Table 4

SPE absolute recoveries of analytes from spiking concentrations of $10 \mathrm{ng} \mathrm{L}^{-1}$ and $100 \mathrm{ng} \mathrm{L}^{-1}, \mu( \pm \sigma) \%$.

\begin{tabular}{|c|c|c|c|c|c|c|}
\hline \multirow[t]{2}{*}{ Analytes } & \multicolumn{2}{|c|}{ Ultra pure water $n=7$} & \multicolumn{2}{|c|}{ Tap water $n=7$} & \multicolumn{2}{|c|}{ Tertiary treated effluent $n=7$} \\
\hline & $10 \mathrm{ng} \mathrm{L}^{-1}$ & $100 \mathrm{ng} \mathrm{L}^{-1}$ & $10 \operatorname{ng~L}^{-1}$ & $100 \mathrm{ng} \mathrm{L}^{-1}$ & $10 \mathrm{ng} \mathrm{L}^{-1}$ & $100 \mathrm{ng} \mathrm{L}^{-1}$ \\
\hline NDMA & $43(27)$ & $51(23)$ & $79(13)$ & $52(9)$ & * & $79(17)$ \\
\hline NMEA & $55(23)$ & $71(10)$ & $62(12)$ & $72(5)$ & 71 (19) & $80(9)$ \\
\hline NDEA & $66(16)$ & $82(5)$ & $72(7)$ & $85(4)$ & & $84(7)$ \\
\hline NDPA & $83(8)$ & $93(6)$ & $87(4)$ & $93(4)$ & $86(7)$ & $93(5)$ \\
\hline NMorph & $83(7)$ & $89(6)$ & $86(5)$ & $93(3)$ & & $101(8)$ \\
\hline NPyr & $52(24)$ & $63(12)$ & $63(12)$ & $69(5)$ & $70(14)$ & $79(8)$ \\
\hline NPip & $72(12)$ & $78(6)$ & $76(7)$ & $83(3)$ & $*$ & $88(3)$ \\
\hline NDBuA & $90(11)$ & $92(3)$ & $93(10)$ & $94(5)$ & ${ }^{*}$ & $93(4)$ \\
\hline
\end{tabular}

* Background levels were observed for these compounds in tertiary treated effluent.

These results emphasize the importance of isotope dilution for SPE recovery correction among diverse matrices.

\subsection{Electron ionisation optimisation}

Optimization of the mass spectral parameters was undertaken in order to enhance the sensitivity of detection in EI mode. Careful attention was paid to the selection of suitable MRM transitions to produce product ions of high intensity and minimal interference. Once these transitions were selected, product ion formation was optimised by running numerous experiments at variable collision energies (between 0 and $40 \mathrm{~V}$ ). Dwell times were adjusted to ensure sufficient peak definition.

Electron ionization is regarded as being a 'hard' ionization technique, compared to most chemical ionization processes which are typically considered to be 'soft' ionization techniques. This means that EI tends to result in greater fragmentation of the molecular ion compared to $\mathrm{CI}$ (which may not lead to fragmentation at all). This can lead to a loss of sensitivity, especially for small molecules such as NDMA (MW of $74 \mathrm{amu}$ ). In the optimized method, the selected precursor ion was in all cases the molecular ion. Tests were undertaken to optimize the formation of the molecular ion by decreasing the ionization energy. To do this, the electron ionization energy was decreased from the nominal 70 . to $60,50,40$ and $30 \mathrm{eV}$. However, in all cases this did not further improve the formation of the molecular ion. This is shown by observation of the NDMA MRM transition $m / z 74 \rightarrow 44.1$ in Fig. 2 . All other nitrosamines showed similar decrease in response with decreasing electron ionization energies.

Change in MS source temperature afforded significant increase in peak area with higher temperature. Fig. 3 shows a $100 \mathrm{ng}$ NDMA peak under increasing source temperatures. From these experiments it was observed that $300{ }^{\circ} \mathrm{C}$ was the optimum source temperature for NDMA, with lower ion formation observed at $250{ }^{\circ} \mathrm{C}$ and $350{ }^{\circ} \mathrm{C}$. Other nitrosamines showed slight reduction of response at $300{ }^{\circ} \mathrm{C}$ so an ion source temperature of $280^{\circ} \mathrm{C}$ was selected for an overall optimization of response for all nitrosamines.

\subsection{Method detection levels}

In previously reported methods, the approach taken to determine the analytical detection limit has been varied (and often not explicitly stated). The most common procedure has been to identify an analyte concentration for which a signal-to-noise ratio $(\mathrm{S} / \mathrm{N})$ of 3 can be obtained. The concentration obtained by this approach is most correctly termed the 'lower level of detection' (LLD) or the 'level of detection' (LOD) [28]. This approach is intended to set the probability of both false positives and false negatives at 5\%. However, the LLD method is not well suited to GC-MS/MS analysis since it is commonly not possible to observe any 'noise' (see Fig. 1). A more robust (but somewhat more conservative) approach for defining detection limits is adopted in this study and is referred to as the 'method detection level' (MDL). The MDL is used to describe the analyte concentration that, when processed through the complete method, produces a signal with a $99 \%$ probability that it is different from the blank [28]. In ultrapure water and tap water, MDLs typically ranged between 0.4 and $1.7 \mathrm{ng} \mathrm{L}^{-1}$ (Table 5). The MDLs of NMEA, NDPA and NPyr in tertiary treated effluent ranged between $0.9 \mathrm{ng} \mathrm{L}^{-1}$ and $4 \mathrm{ng} \mathrm{L}^{-1}$ (Table 5). Determination of MDLs of the other $N$-nitrosamines in this matrix was not possible because of the occurrence of these compounds in un-spiked tertiary treated effluent (see analyte recovery experiments section above).

\subsection{Instrument stability, matrix effects and calibration range}

The results of instrument and method stability assessments are presented in Table 6 . The coefficients of variability $\left(C_{v}=\sigma / \mu\right)$ on an intra-day basis ranged from 0.01 to 0.09 . Slightly greater 


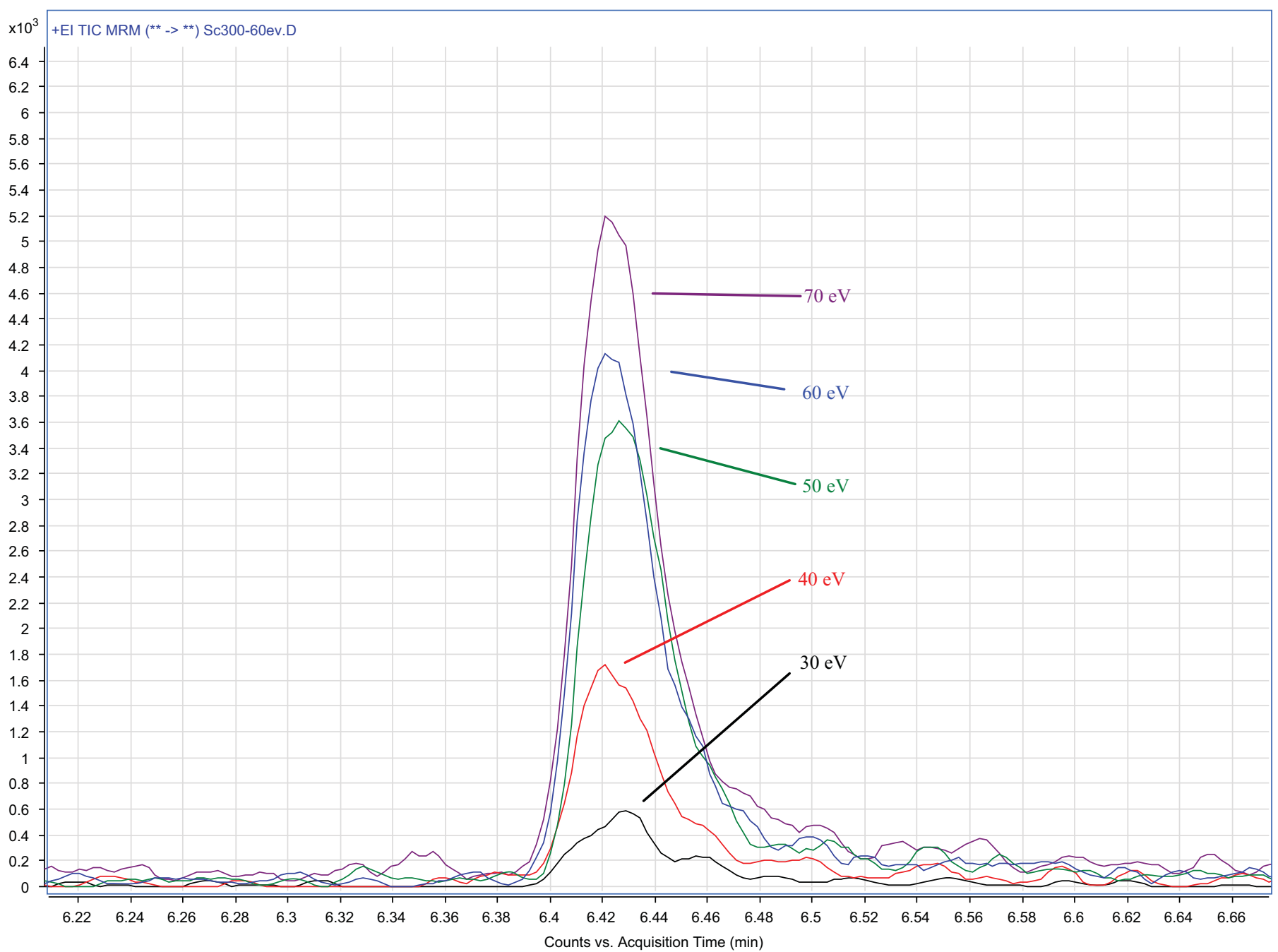

Fig. 2. Effect of decreasing electron energy on $100 \mathrm{ng}$ sample of NDMA. Decreased electron energy led to a decrease in ionization rather than decreased fragmentation of the molecular ion.

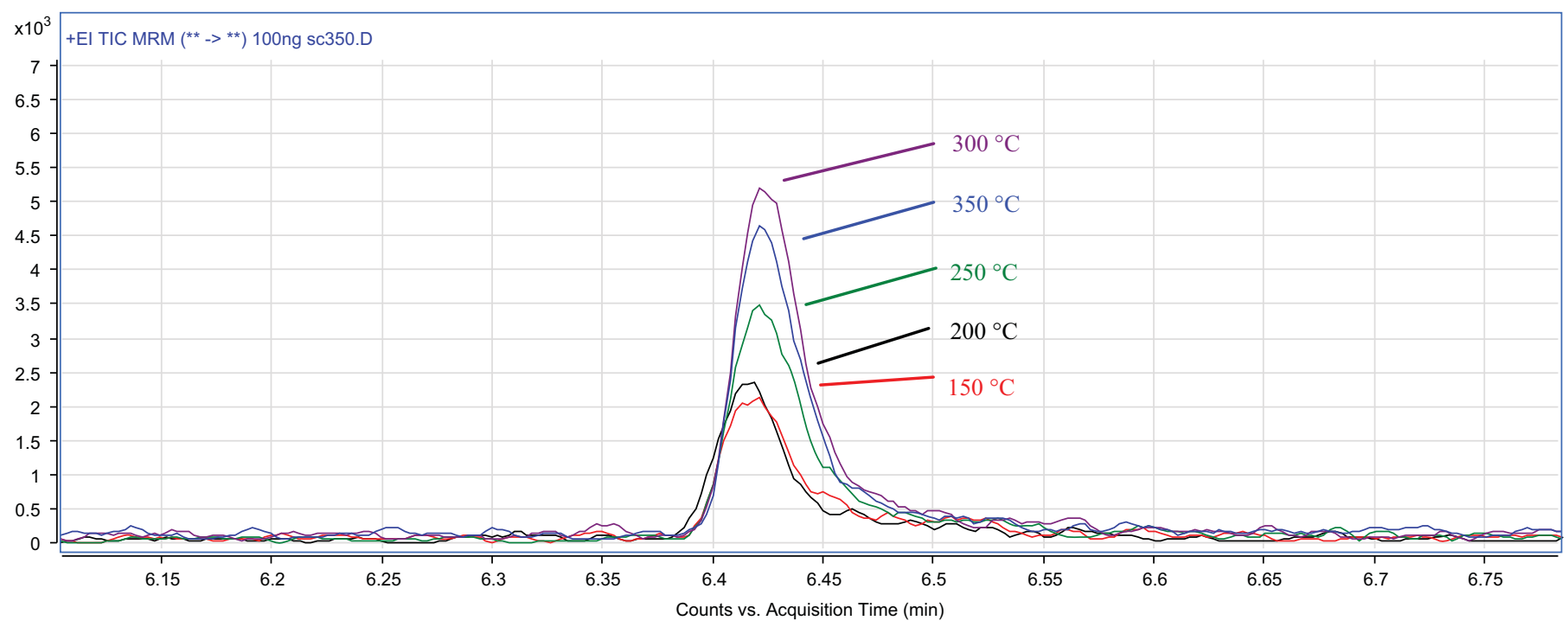

Fig. 3. Effect of ion source temperature on NDMA response (Legends: red-150 ${ }^{\circ} \mathrm{C}$; black $-200{ }^{\circ} \mathrm{C}$; green-250 ${ }^{\circ} \mathrm{C}$; purple-300 ${ }^{\circ} \mathrm{C}$; Blue $-350{ }^{\circ} \mathrm{C}$ ). An optimum source temperature of $300{ }^{\circ} \mathrm{C}$ was identified for NDMA, but $280^{\circ} \mathrm{C}$ was more generally optimal for all analytes. 
Table 5

Instrument detection limits (IDL) and method detection limits (MDL) of target analytes in three water matrices.

\begin{tabular}{|c|c|c|c|c|}
\hline Analyte & IDL pg (on column) & Ultra pure water MDL $\left(\operatorname{ng~L}^{-1}\right) n=7$ & Tap water MDL $\left(\operatorname{ng~L}^{-1}\right) n=7$ & Tertiary treated effluent MDL $\left(\operatorname{ng~L~}^{-1}\right) n=7$ \\
\hline NDMA & 0.3 & 0.45 & 0.81 & ${ }^{*}$ \\
\hline NMEA & 0.3 & 0.55 & 0.64 & 0.9 \\
\hline NDEA & 0.1 & 0.94 & 0.83 & $*$ \\
\hline NDPA & 0.1 & 0.83 & 0.96 & 2.7 \\
\hline NMorph & 0.3 & 0.67 & 0.43 & \\
\hline NPyr & 0.9 & 1.16 & 1.50 & 4.0 \\
\hline NPip & 0.2 & 0.91 & 0.67 & $*$ \\
\hline NDBuA & 0.2 & 1.66 & 1.14 & ${ }^{*}$ \\
\hline
\end{tabular}

Note: injection volume is $1 \mu \mathrm{L}$, thus $1 \mathrm{ng} \mathrm{L}^{-1}$ is equal to $1 \mathrm{pg}$ on column mass.

* MDLs for these compounds in tertiary treated effluent were unable to be determined due to background levels in this matrix.

Table 6

Coefficient of variation $C_{v}=\sigma / \mu$ for instrument stability and method stability of target analytes in various water matrices.

\begin{tabular}{|c|c|c|c|c|c|c|}
\hline \multirow[t]{3}{*}{ Analytes } & \multirow{2}{*}{\multicolumn{2}{|c|}{$\begin{array}{l}\text { Instrument stability } \\
\text { Standard } 100 \mathrm{ng} \mathrm{mL}^{-1}\end{array}$}} & \multicolumn{4}{|c|}{ Method stability } \\
\hline & & & \multicolumn{2}{|c|}{ Tap water $100 \mathrm{ng} \mathrm{L}^{-1}$} & \multicolumn{2}{|c|}{ Tertiary treated effluent $100 \mathrm{ng} \mathrm{L}^{-1}$} \\
\hline & Intra-day $n=3$ & Inter-day $n=6$ & Intra-day $n=3$ & Inter-day $n=6$ & Intra-day $n=3$ & Inter-day $n=6$ \\
\hline NDMA & 0.01 & 0.03 & 0.06 & 0.06 & 0.07 & 0.06 \\
\hline NMEA & 0.02 & 0.02 & 0.04 & 0.03 & 0.05 & 0.06 \\
\hline NDEA & 0.01 & 0.01 & 0.04 & 0.05 & 0.07 & 0.05 \\
\hline NDPA & 0.06 & 0.09 & 0.09 & 0.09 & 0.09 & 0.08 \\
\hline NMorph & 0.01 & 0.04 & 0.03 & 0.05 & 0.05 & 0.04 \\
\hline NPyr & 0.01 & 0.04 & 0.05 & 0.04 & 0.09 & 0.08 \\
\hline NPip & 0.01 & 0.02 & 0.03 & 0.04 & 0.05 & 0.05 \\
\hline NDBuA & 0.04 & 0.04 & 0.05 & 0.05 & 0.06 & 0.04 \\
\hline
\end{tabular}

a Instrument stability not corrected by isotope dilution.

b Method stability includes correction by isotope dilution.

Table 7

Signal enhancement/suppression in surface water and tertiary treated effluent matrices from a spiking concentration of $10 \mathrm{ng} \mathrm{L}^{-1}, \mu( \pm \sigma) \%$.

\begin{tabular}{lll}
\hline & Tap water matrix $\boldsymbol{n}=\mathbf{3}$ & Tertiary treated effluent matrix $\boldsymbol{n}=\mathbf{3}$ \\
\hline NDMA & $-11( \pm 8)$ & $-10( \pm 9)$ \\
NMEA & $-10( \pm 8)$ & $-10( \pm 10)$ \\
NDEA & $-11( \pm 9)$ & $-7( \pm 12)$ \\
NDPA & $-8( \pm 8)$ & $-6( \pm 12)$ \\
NMorph & $-11( \pm 8)$ & $-7( \pm 13)$ \\
NPyr & $-12( \pm 10)$ & $-8( \pm 16)$ \\
NPip & $-10( \pm 6)$ & $-7( \pm 12)$ \\
NDBuA & $-19( \pm 10)$ & $-0( \pm 17)$ \\
\hline
\end{tabular}

coefficients of variability for instrument variability were observed on an inter-day basis, from 0.01 to 0.09 . Coefficients of variability for the full method analysis of spiked tap water and tertiary effluent samples on both an intra-day and inter-day basis were observably higher. These varied from 0.04 to 0.09 and this observation emphasises the important of the isotope dilution process to ensure a high level of analytical reproducibility.

The results of the signal enhancement/suppression assessment in surface water and tertiary treated effluent matrices are presented in Table 7. This data represent the means and standard deviations of three samples assessed in each of the two matrices. Signal suppression was evident for all analytes. In tap water this ranged between $8 \%$ and $19 \%$ and $0 \%$ and $10 \%$ for tertiary treated effluent. While these results show less overall signal suppression in the tertiary treated effluent, large relative standard deviations for this matrix reveal a high degree of variability thus obscuring any real trends. This variability again reinforces the importance of isotope dilution for accurate quantification in real sample matrices.
The linear calibration range for the target compounds was determined to be from their identified MDLs to $400 \mathrm{ng} \mathrm{L}^{-1}$, thus the upper quantification limit is $400 \mathrm{ng} \mathrm{L}^{-1}$ for all analytes. The calibration points for each of the analytes were fitted to linear regressions and the calibration curve regression correlation coefficients were always at least 0.99 for all sample batches.

\section{Conclusion}

A rapid analytical method was developed for the analysis of eight $N$-nitrosamines in aqueous matrices. While closely following previously developed extraction procedures this is the first method to employ GC coupled to tandem mass spectrometry using electron impact ionisation rather than chemical ionisation. The use of GC-MS/MS has enabled unambiguous identification and non-interfering quantification of closely eluting chromatographic peaks in a very short analysis time of only $14 \mathrm{~min}$.

The use of isotope dilution for all analytes ensures the accurate quantification, accounting for analytical variability that may be introduced during sampling, extraction, chromatography, ionisation or mass spectrometric detection.

The established MDLs for most analytes were $0.4-4 \mathrm{ng} \mathrm{L}^{-1}$ in a variety of aqueous matrices. Higher MDLs were observed for analytes in tertiary treated effluent however determination of this and other validation parameters was hindered by background concentration in this matrix. The method validation confirmed good method stability over intra-day and inter-day analyses.

\section{Acknowledgements}

This work was supported by the Australian Research Council Linkage Projects LP0989365 (with industry support from Veolia 
Water and Seqwater). Additional funding and technical assistance was provided by Agilent Technology. The Authors thank $\mathrm{Mr}$ Jackson Wong for his assistance with sample extraction and Sydney Water for providing tertiary treated effluent for method validation studies.

\section{References}

[1] A. Ayanaba, M. Alexander, J. Environ. Qual. 3 (1974) 83-89.

[2] J. Choi, R.L. Valentine, Water Res. 36 (2002) 817-824.

[3] W.A. Mitch, D.L. Sedlak, Environ. Sci. Technol. 36 (2002) 588-595.

[4] W.A. Mitch, J.O. Sharp, R.R. Trussell, R.L. Valentine, L. Alvarez-Cohen, D.L. Sedlak, Environ. Eng. Sci. 20 (2003) 389-404.

[5] Y.-Y. Zhao, J.M. Boyd, M. Woodbeck, R.C. Andrews, F. Qin, S.E. Hrudey, X.-F. Li, Environ. Sci. Technol. 42 (2008) 4857-4862.

[6] A.D. Shah, W.A. Mitch, Environ. Sci. Technol. 46 (2012) 119-131.

[7] J.M. Kemper, S.S. Walse, W.A. Mitch, Environ. Sci. Technol. 44 (2010) 1224-1231.

[8] S.-H. Park, S. Wei, B. Mizaikoff, A.E. Taylor, C.d. Favero, C.-H. Huang, Environ. Sci. Technol. 43 (2009) 1360-1366.

[9] M. Krauss, P. Longree, F. Dorusch, C. Ort, J. Hollender, Water Res. 43 (2009) 4381-4391.

[10] S.W. Krasner, P. Westerhoff, B.Y. Chen, B.E. Rittmann, G. Amy, Environ. Sci. Technol. 43 (2009) 8320-8325.

[11] Safe Drinking Water Act, Ontario Regulation 169/03: Ontario Drinking Water Quality Standards, (2002).

[12] Health Canada, Federal-Provincial-Territorial Committee on Drinking Water: Guideline Technical Document on $N$-nitrosodimethylamine (NDMA) in Drinking Water for public comment. Website: 〈http://www.hc-sc.gc.ca/ ewh-semt/consult/_2010/ndma/index-eng.php $\rangle, 2010$.

[13] Environmental Protection Agency, Drinking Water Contaminant Candidate List 3-Final. EPA-HQ-OW-2007-1189 FRL-8963-6, 2009.
[14] Natural Resource Management Ministerial Council, Environment Protection and Heritage Council, National Health and Medical Research Council, in: National Water Quality Management Strategy, Canberra, 2008.

[15] World Health Organization, Guidelines for drinking-water quality, fourth edition, 2011.

[16] National Water Quality Management Strategy, Australian Drinking Water Guidelines, National Health and Medical Research Council, Natural Resource Management Ministerial Council-Government of Australia, Canberra, 2011.

[17] A. Hebert, D. Forestier, D. Lenes, D. Benanou, S. Jacob, C. Arfi, L. Lambolez, Y. Levi, Water Res. 44 (2010) 3147-3165.

[18] J.W. Munch, M.V. Bassett, In, National Exposure Research Laboratory, Office of Research and Development, US EPA., Cincinnati, Ohio, 2004.

[19] J.W. Munch, M.V. Bassett, J. AOAC Int. 89 (2006) 486-497.

[20] H.W. Hung, T.F. Lin, C.H. Chiu, Y.C. Chang, T.Y. Hsieh, Water Air Soil Pollut 213 (2010) 459-469.

[21] A. Llop, F. Borrull, E. Pocurull, J. Sep. Sci. 33 (2010) 3692-3700.

[22] Y.Y. Zhao, J. Boyd, S.E. Hrudey, X.F. Li, Environ. Sci. Technol. 40 (2006) 7636-7641.

[23] M.H. Plumlee, M. Lopez-Mesas, A. Heidlberger, K.P. Ishida, M. Reinhard, Water Res. 42 (2008) 347-355.

[24] C. Ripollés, E. Pitarch, J.V. Sancho, F.J. López, F. Hernández, Anal. Chim. Acta 702 (2011) 62-71.

[25] C. Planas, O. Palacios, F. Ventura, J. Rivera, J. Caixach, Talanta 76 (2008) 906-913.

[26] Y.Y. Zhao, X. Liu, J.M. Boyd, F. Qin, J.J. Li, X.F. Li, J. Chromatogr. Sci. 47 (2009) 92-96.

[27] M. Possanzini, A. Pela, A. Liberti, G.P. Cartoni, J. Chromatogr. A 38 (1968) $492-497$.

[28] A.D. Eaton, L.S. Clesceri, E.W. Rice, A.E. Greenberg (Eds.), American Public Health Association, Washington DC, USA, 2005.

[29] D. Feng, H.P. Wang, X.L. Cheng, J.D. Wang, L.F. Ning, Q.F. Zhou, Y. Zhou, Q.L. Yang, Int. J. Hyg. Environ. Health 212 (2009) 533-540.

[30] J.M. Kemper, P. Westerhoff, A. Dotson, W.A. Mitch, Environ. Sci. Technol. 43 (2009) 466-472.

[31] T. Fujioka, L.D. Nghiem, S.J. Khan, J. McDonald, Y. Poussade, J.E. Drewes, J. Membr. Sci., 409-410 (2012) 66-74. 